BULLETIN Bulletin hispanique

HISPANIQUE Université Michel de Montaigne Bordeaux

$119-2 \mid 2017$

La Égloga renacentista en el Reino de Nápoles

\title{
El género bucólico en Nápoles
}

de la Arcadia de Sannazaro a la Égloga segunda de Garcilaso

\section{Antonio Gargano}

\section{OpenEdition}

Journals

Edición electrónica

URL: http://journals.openedition.org/bulletinhispanique/5106

DOI: 10.4000/bulletinhispanique.5106

ISSN: 1775-3821

Editor

Presses universitaires de Bordeaux

Edición impresa

Fecha de publicación: 1 diciembre 2017

Paginación: 573-590

ISBN: 979-10-300-0218-8

ISSN: 0007-4640

Referencia electrónica

Antonio Gargano, «El género bucólico en Nápoles», Bulletin hispanique [En línea], 119-2 | 2017,

Publicado el 28 diciembre 2020, consultado el 13 enero 2021. URL: http://journals.openedition.org/

bulletinhispanique/5106 ; DOI: https://doi.org/10.4000/bulletinhispanique.5106 


\title{
El género bucólico en Nápoles: de la Arcadia de Sannazaro a la Égloga segunda de Garcilaso
}

\author{
Antonio Gargano \\ Università degli Studi di Napoli Federico II
}

Dans sa Deuxième Églogue, Garcilaso de la Vega cherche à s'essayer aux solutions que Jacques Sannazar avait données, dans son Arcadie, à trois grandes questions: l'unité et la cohérence de l'œuvre; la combinaison de genres littéraires et la conception du genre bucolique; la valeur idéologique et le contexte historique : autant de solutions auxquelles le poète de Tolède ne se conforma pas toujours.

Mots-clés: Garcilaso de la Vega, Deuxième Églogue, Jacques Sannazar, Arcadie, Virgile, Bucoliques.

En su Égloga segunda, Garcilaso de la Vega quiso medirse con las soluciones que Jacopo Sannazaro había dado en la Arcadia a tres grandes cuestiones: unidad y coherencia de la obra, combinación de géneros literarios y concepción del género bucólico, valor ideológico y contexto histórico; soluciones a las que el poeta toledano no siempre se amoldó.

Palabras clave: Garcilaso de la Vega, Égloga segunda, Iacopo Sannazaro, Arcadia, Virgilio, Bucólicas.

In his 'Egloga segunda', Garcilaso de la Vega desired to try his hand to the solutions Jacopo Sannazaro had offered in his 'Arcadia' about three important issues: the work unity and coherence; the combination of the genres; the conception of the Bucolic genre, his ideological value and his historical context. The Toledo poet nevertheless not always conformed to these answers.

Keywords: Garcilaso de la Vega, Second Eclogue, Iacopo Sannazaro, Arcadia, Virgil, Bucolics. 
$\mathrm{D}$

os décadas exactas separan la composición de la Égloga segunda de la edición aldina de la Arcadia, "punto di partenza della vulgata cinquecentesca» de la obra maestra de Jacopo Sannazaro ${ }^{1}$. En los veinte años en cuestión, o, si se prefiere, en los treinta años que distancian el primer experimento bucólico de Garcilaso de la princeps de la Arcadia, publicada por el humanista Pietro Summonte en marzo de 1504, muchos sucesos significativos habían caracterizado la producción poética de la ciudad partenopea. Pese a ello, por lo que se refiere al estado del género bucólico en vulgar en el periodo mencionado, la égloga se compuso solo en latín: en esto, poetas como Egidio da Viterbo, Pomponio Gaurico, Girolamo Angeriano y Giano Anisio siguieron, básicamente, el ejemplo del propio Sannazaro, quien, de vuelta del exilio francés en la primavera de 1505, ampliaba a cinco las Eclogae piscatoriae, dejando sin acabar un fragmento de la sexta ${ }^{2}$. Habrá que esperar a la cuarta década del siglo para asistir en Nápoles al renacimiento de la égloga en vulgar. En apenas un lustro, un grupo de poetas, todos -o casi todos- amigos de Garcilaso, promovieron su despertar: al inicio de la década se remontaría, en efecto, I due pellegrini de Tansillo; entre el 31 y el 34, Bernardo Tasso compuso las siete églogas que una vez publicadas formaron una sección aparte en la segunda edición de los Amores; en el 33, Bernardino Rota componía 13 églogas piscatorias, que salieron impresas muchos años más tarde; al 35, por último, se remontan las tres églogas de Antonio Minturno, con las que se introdujo en Nápoles la novedad métrica del género: la égloga en endecasílabos sueltos que, fuera de Nápoles, a partir del ejemplo de Alemanni, seguido inmediatamente por Trissino, acabó por imponerse en detrimento de la solución que adoptaba los tercetos ${ }^{3}$.

1. Carlo Vecce, «Viaggio in Arcadid», en Jacopo Sannazaro, Arcadia, ed. Carlo Vecce, Roma, Carocci, 2013, p. 46.

2. Carlo Vecce, "L'egloga Melisaeus di Giano Anisio tra Pontano e Sannazaro", en Stefano Carrai (ed.), La poesia pastorale nel Rinascimento, Padova, Antenore, 1998, pp. 213-234, esp. pp. 213-216.

3. Sobre el desarrollo de la égloga quinientista resulta todavía útil Enrico Carrara, La poesia pastorale, Milano, Vallardi, 1909, p. 383 y ss. Sobre la lírica pastoril italiana del siglo XVI, cf. el reciente trabajo de Giovanni Ferroni, Dulces lusus. Lirica pastorale e libri di poesia nel Cinquecento, Alessandria, Edizioni dell'Orso, 2012. I due pellegrini de Tansillo es accesible solo en la vieja edición contenida en L'egloga e i poemetti, ed. Francesco Flamini, Napoli, Biblioteca napoletana di storia e letteratura, 1893, pp. 1-46. Una próxima edición de $I$ due pellegrini está prevista en L'egloga e i poemetti, vol. IV de la Edizione delle opere di Luigi Tansillo, coordinada por Tobia R. Toscano, Roma, Bulzoni. Sobre esta composición pueden leerse las páginas de Francesco Tateo, "Giardino principesco e Paradiso biblico», en Chierici e feudatari del Mezzogiorno, Roma-Bari, Laterza, 1984, pp. 115-143, esp. pp. 120-125. Para las églogas de Tasso y de Rota, véanse ahora: Bernardo Tasso, Rime, ed. Domenico Chiodo, Turín, Res, 1995, vol. I, pp. $261-$ 287; Bernardino Rota, Egloghe piscatorie, Torino, Res, 1990. En fin, por lo que se refiere a las composiciones bucólicas de Alamanni y Trissino, se puede recurrir a Luigi Alamanni, Versi e prose, ed. Piero Raffaelli, Firenze, Le Monnier, 1859, 2 vols.; Gian Giorgio Trissino, Rime 1529, ed. Amedeo Quondam, Vicenza, Neri Pozza, 1981. Sobre la égloga en versos sueltos puede consultarse Luciana Borsetto, "L’egloga in sciolti nella prima metà del Cinquecento. Appunti sul liber di Girolamo Muzio», en Miscellanea di studi in onore di Giovanni Da Pozzo, Roma- 
Es en este contexto en el que Garcilaso de la Vega decidió componer la primera de sus tres églogas, que el poeta escribió «al año o año y medio de su residencia en Nápoles», y que -con palabras del mismo Rafael Lapesadebió de terminar de componer «entre mayo de 1533 y los primeros meses de $1534{ }^{4}$, o -como ha precisado Bienvenido Morros en un reciente trabajo- entre abril de 1533 y el mismo mes del año siguiente ${ }^{5}$ o sea, justo en el momento culminante del mencionado lustro que marcó el renacimiento de la égloga en vulgar en Nápoles ${ }^{6}$. Solo que, con una actitud que es una constante en él, Garcilaso prefiere siempre el contacto directo con los grandes modelos, ya sean clásicos o vulgares, lo que se verifica -dicho a modo de inciso- incluso cuando el arranque inspirador de alguna composición suya es detectable en los versos de alguno de sus contemporáneos o, también, de algún poeta amigo: en estos casos, la sugerencia inicial es abandonada de inmediato, o mejor, esta se le ofrece exclusivamente como punto de partida, sirviendo así de estímulo para contactar y medirse con los grandes modelos del pasado, más o menos cercanos ${ }^{7}$. En el caso de la égloga segunda, sin ninguna duda, Garcilaso fue motivado a experimentar el género pastoril en su lengua, a partir del contexto poético partenopeo de los primeros años treinta, al que he aludido brevemente, pero lo hizo confrontándose -más que con sus estrechos contemporáneos o amigos- directamente con el poeta napolitano que ya gozaba de inmenso prestigio inmediatamente después de su muerte, acaecida en 1530; y lo hizo dirigiendo su atención -más que a los productos que se estaban elaborando en aquel lapso de tiempo- al modelo indiscutible del género bucólico en vulgar, la Arcadia de Sannazaro.

El encuentro con la obra maestra del napolitano se produjo de la forma más dócilmente rentable, es decir, a través de la traducción y transcodificación de los

Padova, Antenore, 2004, pp. 123-161, luego recogido en Andar per l'aria: temi, miti, generi nel Rinascimento e oltre, Ravenna. Longo, 2009.

4. Rafael Lapesa, Garcilaso: Estudios completos, Madrid, Istmo, 1985, p. 96 y p. 180.

5. Bienvenido Morros, «Albanio como don Fernando de Toledo en la Égloga II de Garcilaso», Analecta Malacitana, vol. XXXI, $\mathrm{n}^{\circ}$ 1, 2008, p. 9.

6. Se ha observado, justamente, que aunque sea indudable que «todos los rastros que han quedado ponen sin excepción en evidencia que la integración de Garcilaso en Nápoles a partir de 1532 fue inmediata y total», es igualmente cierto que "antes de acudir a Italia Garcilaso debía estar en más de un sentido a la altura de cualquier poeta instruido y brillante de la corte napolitana» (Eugenia Fosalba, "A vueltas con el descuido de Garcilaso y Boscán», en La escondida senda. Estudios en homenaje a Alberto Blecua, Madrid, Castalia, 2012, p. 150).

7. La observación de Francisco Rico sobre la Elegía primera de Garcilaso se puede extender a una gran parte de la poesía del toledano, que «se vuelve una indagación de su propia genealogía, de su posición en la serie literaria: es a un tiempo poesía e historia de la poesía; y el genio de Garcilaso se desarrolla al devanar la madeja de esa historia, en un doble impulso de homenaje y desafío a los modelos» («La tradición y el modelo», en Breve biblioteca de autores españoles, Barcelona, Seix Barral, 1990, p. 286). Además de la elegía, un buen ejemplo de ello es la Ode ad florem Cnidi, como intenté demostrar, entre otros, en «La oda entre Italia y España en la primera mitad del siglo XVI», trabajo recogido en Antonio Gargano, Con canto acordado. Estudios sobre la poesía entre Italia y España en los siglos XV-XVII, Sevilla, Secretariado de Publicaciones de la Universidad de Sevilla, 2012, pp. 191-216, esp. pp. 211-216. 
casi quinientos versos que encierran la narración de Albanio, divididos -como se recordará- en dos partes debido a la interrupción del narrador provocada por el tormento de la memoria, a la que sigue -antes de volver a ella- un nuevo diálogo con Salicio, destinatario y obstinado instigador de dicha narración ${ }^{8}$.

Como es de sobra sabido, la deuda con la Arcadia fue puntualmente señalada por el primer comentarista de la égloga garcilasiana, el Brocense, quien, en la concisa nota que dedicó al argumento, logró entrelazar la indicación de la fuente con un juicio estético lapidariamente ambiguo: «Esta narración -escribió el Brocense, refiriéndose al relato de Albanio- a la larga que dura siete u ocho hojas, está con grande ingenio traducida de la prosa octava de Sannazaro" ${ }^{9}$.

En tiempos mucho más recientes, el ambiguo juicio del salmantino profesor de retórica ha sido retomado por el ya mencionado maestro de los estudios garcilasianos, quien ha sostenido que «los quinientos versos inspirados en Sannazaro dan la impresión de forzado alargamiento» ${ }^{10}$. Una dilatación juzgada hasta tal punto inconveniente que, para justificarla, el mismo Lapesa ha hipotetizado una originaria redacción de la égloga circunscrita a «un núcleo primero constituido por una pastoral de Albanio y Camila sin prolijidades narrativas ${ }^{11}$, a la que, en una segunda fase, se habrían añadido, por un lado, la descripción de la urna mágica con las empresas del duque de Alba y los hechos de sus antepasados, y a la que, por otro lado, por un criterio de simetría, se habría agregado contextualmente un alargamiento de las narraciones de Albanio. Confieso que tal hipótesis sobre la construcción del texto no me convence del todo, fundamentalmente porque -en mi opinión- el ejercicio imitativo a partir de la prosa sannazariana debió de servir a Garcilaso de estímulo primario en la experimentación de un particular tipo de lenguaje lírico. Por otra parte, si se leen con atención los textos de la famosa controversia sobre las Anotaciones herrerianas es imposible evitar el convencimiento de que también el poeta y teórico sevillano era propenso a conceder su favor a la práctica imitativa con respecto al canon estético de la brevitas y de la convenientia. En la primera y larga nota de comentario sobre la narración de Albanio, Herrera, a su vez, no puede evitar reprobar esta prolijidad, dado que el pastor «cuenta muchas particularidades que podrían parecer demasiadas a los que son amigos de la brevedad y moderación» ${ }^{12}$. Sin embargo, la página que sigue a la explícita

8. Para las «modalidades formales con las que la traducción en versos se realiza», permítaseme remitir a Antonio Gargano, "De Sannazaro a Garcilaso: traducción y transcodificación (a propósito de la Égloga II)», en Pierre Civil, Antonio Gargano, Matteo Palumbo y Encarnación Sánchez García (eds.), Fra Italia e Spagna: Napoli crocevia di culture durante il Vicereame, Napoli, Liguori, 2011, pp. 117-130.

9. Antonio Gallego Morell, Garcilaso de la Vega y sus comentaristas, Madrid, Gredos, 1972, p. 288 (B. 142).

10. Lapesa, op. cit., p. 97.

11. Ibid., p. 100.

12. Fernando de Herrera, Anotaciones a la poesía de Garcilaso, ed. Inoria Pepe Sarno y José María Reyes Cano, Madrid, Cátedra, 2001, p. 820. 
censura, a la hora de tejer la alabanza de los versos, por otro lado censurados, testimonia con absoluta eficacia cómo al antiguo comentarista le resultaba absolutamente claro que "la grande elegancia i hermosura» de los versos en cuestión ofrecía una prueba más del hecho de que «ninguna cosa se puede pensar que no se declare bien en nuestra lengua i que ninguna ai tan difícil en las agenas que no l'alcance la nuestra», con el resultado - a fin de cuentas- de que el castellano había alcanzado la misma dignidad literaria que el toscano ${ }^{13}$. Una confirmación de esto se puede encontrar en la concisa respuesta que, sobre este argumento, Herrera da al Prete Jacopín. A este, que le censura el carácter capcioso de la crítica e, incluso, la torpeza para entender el modo de pensar de un infeliz enamorado ${ }^{14}$, Herrera replica reafirmando la posición ya expresada sobre la "dulçura i elegancia» de los versos, en contraste con su "prolijidad", "porque bien vê - así concluye el sevillano- que fue talante de traduzir a Sanazaro, antes que necesidad del lugar» ${ }^{15}$. Lo que Herrera no dice explícitamente, aunque lo deja entender claramente tan solo con tener la diligencia de conectar los argumentos de la nota inicial con la afirmación de la réplica a su opositor, es que, gracias al talante o voluntad de Garcilaso en traducir a Sannazaro, de la moderna prosa exquisitamente lírica italiana, o mejor, "poético-narrativa», como ha sido definida ${ }^{16}$, tuvo origen la moderna poesía exquisitamente narrativa española. Porque si, como ha escrito Maria Corti, «il Sannazaro è di quei poeti che provano più stupore davanti alle parole che alle $\operatorname{cose}{ }^{17}{ }^{17}$, no es menos cierto que Garcilaso debió de inclinarse a un análogo estupor ante la lectura de las palabras del napolitano, hasta querer nutrir con ellas su increíble talento y su arte genial. Y también, porque el estupor de nuestro poeta debió de aumentar frente a la que aparecía como la mayor novedad de la Arcadia y que consistía, sin duda alguna, en la invención del libro estructurado que suponía la superación de las églogas sueltas, cuya presencia se justificaba ahora en relación con el conjunto más orgánico del prosímetro que las contenía. En este sentido, las deudas de Garcilaso contraídas con la Arcadia en su égloga segunda son tan evidentes y múltiples como para justificar la idea de que en él dominó la deliberada voluntad de medirse con Sannazaro en el terreno de la concepción general de la bucólica, llevando así la relación con el modelo más allá de los límites de la sola, aunque fundamental, elección métrica, o de la macroscópica versificación de la prosa octava, y de otros más puntuales, pero no menos significativos, préstamos textuales ${ }^{18}$.

13. Ibid., p. 820 .

14. Juan Montero, La controversia sobre las Anotaciones herrerianas, Sevilla, Servicio de Publicaciones del Excmo. Ayuntamiento de Sevilla, 1987, pp. 130-131.

15. Ibid., p. 294.

16. Maria Corti, «Il codice bucolico e l'Arcadia di Jacobo Sannazaro» (1968), en Metodi e fantasmi, Milano, Feltrinelli, 1977, p. 301.

17. Ibid., p. 294.

18. Considerada por Lapesa "la mina más explotada» por Garcilaso en su segunda égloga (op. cit., p. 107), a la Arcadia y a sus relaciones con la composición de Garcilaso están dedicadas abundantes páginas del libro de Inés Azar, Discurso retórico y mundo pastoral en la «Égloga 
Indiquemos, por tanto, un punto que resulta tan obvio como indiscutiblemente esencial: en la poesía española, el moderno género bucólico nace de un ejercicio imitativo -y, por qué no, traductivo- de aquel texto que, a su vez, fue el origen del desarrollo de la moderna bucólica italiana y, gracias a su difusión, de la europea. Pero, como trataré de mostrar a lo largo de estas notas, con la necesaria brevedad que requiere la ocasión, la relación de la égloga segunda con la Arcadia sannazariana se revela mucho más compleja de lo que parece, si nos limitamos solamente a la consideración de la adaptación de la prosa con la historia de amor de Carino a los versos del relato amoroso de Albanio: en realidad, en la relación con la obra de Sannazaro, su «mina más explotada» ${ }^{19}$-tal y como justamente ha sido observado-, hay implicados muchos más niveles de realización y de significado de la égloga española, sobre los que cabe hacer alguna reflexión.

Partamos de un par de conclusiones que Rafael Lapesa expone, con su habitual claridad y lucidez, en las magistrales páginas finales dedicadas a la égloga, y que tocan algunas cuestiones que han sido el objeto del debate crítico sobre la obra más discutida del poeta toledano, ya desde la época de los antiguos comentaristas. De hecho, partiendo precisamente del comentario de Herrera, Lapesa observa: «En la égloga II hay bucolismo, comedia, tragedia y poema heroico; y, a pesar de sus bellezas parciales, a veces espléndidas, estos elementos no guardan entre sí toda la cohesión estética deseable» ${ }^{20}$.

segunda» de Garcilaso, Amsterdam, John Benjamins, 1981, pp. 84-119, al igual que las puntuales notas, a pie de página y complementarias, de Bienvenido Morros en su edición de Garcilaso de la Vega, Obra poética y textos en prosa, Barcelona, Crítica, 1985, p. 141 y ss.

19. Lapesa, op. cit., p. 107.

20. Ibid., p. 115, para la «disposición notablemente simétrica», véanse las pp. 98-100. Al carácter hetereogéneo de la égloga, sobre el que ya se había pronunciado primero Herrera (Garcilaso de la Vega y sus comentaristas, op. cit., p. 501, H-503), y a los varios intentos para recomponer su unidad de construcción y de significado está dedicada la mayor parte de las contribuciones críticas sobre la composición, entre las cuales véanse al menos: Audrey Lumsden, «Problems connected with the Second Eclogue of Garcilaso de la Vega», Hispanic Review, vol. XV, 1947, pp. 251-271; Margot Arce de Vázquez, "La Égloga segunda de Garcilaso», Asomante, vol. V, $\mathrm{n}^{\circ} 1,1949$, pp. 57-73 y n² 2, pp. 60-78; Ines Macdonald, «La Égloga II de Garcilaso» (1950), recogido en Elias L. Rivers (ed.), La poesía de Garcilaso, Barcelona, Ariel, 1974, pp. 209-235; Royston O. Jones, «The Idea of Love in Garcilaso's Second Eclogue», Modern Language Review, vol. XLVI, 1951, pp. 388-395; Peter M. Komanecky, «Epic and Pastoral in Garcilaso's Eclogues», Modern Language Notes, vol. LXXXVI, 1971, pp. 154-166; Elias L. Rivers, «Nymphs, Shepherd and Heroes: Garcilaso's Second Eclogue», Philological Quarterly, vol. LI, 1972, pp. 123-134; Pamela Waley, "Garcilaso’s Second Eclogue is a Play», Modern Language Review, vol. LXXII, 1977, pp. 585-596; Inés Azar, Discurso retórico, op. cit., esp. el cap. «La estructura retórica de la Égloga segunda», pp. 120-139; Darío Fernández-Morera, The Lyre and the Oaten Flute: Garcilaso and the Pastoral, London, Tamesis, 1982, pp. 54-72; Stanislaw Zimic, «Las églogas de Garcilaso de la Vega: ensayos de interpretación», Boletin de la Biblioteca de Menéndez Pelayo, no LXIV, 1988, pp. 5-107, esp. pp. 35-78; Antonio Ramajo Caño, «Para la filiación literaria de la Égloga II de Garcilaso», Revista de Literatura, vol. LVIII, 1996, pp. 27-45; Matthew A. Wyszynski, «Friendship in Garcilaso’s Second Eclogue: Thematic Unity and Philosophical Inquiry», Hispanic Review, vol. LXVIII, 2000, pp. 397-414; Angel García Galiano, «Relectura de la Égloga II», Revista de Literatura, vol. LXII, 2000, pp. 19-40. 
En la página siguiente, Lapesa cierra el discurso sobre la égloga con este juicio: «Pese a la construcción y propósito rectores, la unidad intrínseca no [es] perfecta: los desniveles poéticos dejan asomar la heterogeneidad de la composición $»^{21}$.

En los fragmentos citados, las cuestiones son al menos dos, que se encuadran en dos distintos niveles de análisis: por un lado, lo que se le recrimina a la égloga es el defecto de "unidad intrínseca» y, con ello, la falta de "cohesión estética»; por otro lado, esta carencia de unidad y de cohesión se halla en estrecha correlación con la confluencia en la obra de diversos géneros literarios, una mezcla genérica que por la falta del necesario proceso de armonización, sería, en buena medida, responsable de «la heterogeneidad de la composición». En realidad, los géneros que imponen su presencia se pueden reducir a dos: la égloga y el panegírico.

Sin embargo, existe un tercer nivel, con respecto al cual los problemas mencionados de unidad, de cohesión y de heterogeneidad genérica adquieren una relevancia particular y ejercen un papel determinante. Se trata, en concreto, del valor ideológico que es posible atribuir a la égloga de Garcilaso. Con ello pretendo aludir no solo $-\mathrm{y}$ no tanto- al significado de la obra en el sentido amplio del término, sino al significado particular que la misma adquiere en relación con las circunstancias reales y los hechos históricos contemporáneos, a los que la égloga, sobre todo en la segunda parte, hace una constante y puntual referencia. Ni que decir tiene, sin embargo, que esta remisión al contexto real histórico no puede dejar de reflejarse en la primera parte de la composición, que contiene la triste historia del desesperado amor de Albanio. Por lo demás, como ya es sabido, no han faltado numerosas aportaciones críticas, cuyos autores se han esforzado en dar una respuesta a los interrogantes que estos problemas suscitan, dando explicaciones, sea en el plano estrictamente interpretativo de la égloga, sea en el de las relaciones intertextuales con la tradición bucólica y, más en general, con la poética, identificando para tal objetivo modelos específicos a los que Garcilaso se habría inspirado ${ }^{22}$. Por mi parte, siendo coherente con el planteamiento de cuanto he expuesto, adoptaré una perspectiva determinada, la que consiste en considerar las cuestiones surgidas hasta ahora desde la óptica de la relación específica que Garcilaso quiso establecer con el modelo de pastoral que le ofrecía la Arcadia, en su totalidad, es decir, partiendo de la fundamental traducción y transcodificación de la prosa con la historia de Carino, pero sin limitarse solo a ella.

Así pues, en resumidas cuentas, unidad y coherencia de la obra, combinación de géneros literarios y concepción del género bucólico, valor ideológico y contexto histórico: he aquí tres grandes problemas, que se sitúan en otros tantos niveles de realización, pero igualmente relevantes y, sobre todo, enlazados entre sí. Pues bien, en cada uno de estos tres niveles, Garcilaso pretendió medirse

21. Lapesa, op. cit., p. 116.

22. Para la bibliografia sobre estas cuestiones, remito a los estudios citados en la anterior n. 20 . 
con las soluciones que Sannnazaro les había dado en la Arcadia; soluciones a las que no siempre el poeta toledano se amoldó, a pesar de que su interés y su acercamiento al género pastoril habían sido dictados, en larga medida, por la extraordinaria admiración que sintió por la obra maestra del napolitano y por el enorme influjo que dicha obra maestra ejerció sobre él.

Se recordará que en la égloga VIII de la Arcadia la enfermedad de amor condujo al pastor Clonico a insanos propósitos de suicidio, y que entonces Eugenio, afligido por el triste estado de su amigo, le exhorta a que se dedique a las actividades agrestes, porque -es el penúltimo verso de la égloga que pronuncia Eugenio- «al mondo mal non è senza remedio» (v. 150) ${ }^{23}$. En la prosa que sigue a continuación, a los pastores con los que pasa la noche y que al día siguiente le preguntan por el motivo de su partida, Clonico responde que debe alejarse "per trovare a' suoi mali rimedio» (p. 199), pidiendo ayuda a una famosa bruja-hechicera. Algunas líneas más adelante, en la misma prosa IX, Opico, dirigiéndose a Clonico, le dice: «Ben credo, figliuol mio, che gli dii de quali tu sei divoto, ti abbiano qui guidato per farti a' tuoi affanni trovar rimedio» (p. 200), y le propone que se dirija al sabio y anciano pastor consagrado al culto de Pan, Enareto, que -como sabemos- tiene su paralelo en el personaje de Severo de la égloga II de Garcilaso. Pero, por el momento, prestemos atención a los tres breves fragmentos que he citado. En ellos, a propósito de Clonico, se hace referencia cada vez al «remedio del mal», del que sufre el pastor. Detengámonos brevemente en esta fórmula, que, por comodidad, puede ser considerada provisionalmente como clave de lectura general de la Arcadia.

Por lo que se refiere al «mal», desde la primera égloga dedicada por completo al canto desesperado de Ergasto, hasta la conclusiva que contiene el canto de Meliseo «in doglia e lacrime» (v. 62) por la muerte de su amada Filli, casi todas las composiciones insisten en el tema amoroso. En su tratamiento varían los modos y el tono, aunque permanecen sustancialmente fieles al motivo del amor infeliz y del deseo insatisfecho. Así, además de las mencionadas composiciones de apertura y cierre, persisten en el tema los suspiros de Montano y Uranio de la égloga segunda; la canción que Galicio le entona a Amaranta en la tercera; el doble canto de Logisto y Elpino en la cuarta; los lamentos de Sincero y Clonico en las églogas séptima y octava. Naturalmente, el mismo "mal" constituye el núcleo de las historias centrales de Sincero, que se ha hecho pastor y ha abandonado Nápoles por el amor no correspondido de «una picciola fanciulla» (p. 159), y de Carino, que incluso ha intentado el suicidio arrojándose desde un acantilado por amor de una pastora con quien había crecido en compañía desde la infancia.

Considerada desde este punto de vista, la Arcadia no puede más que parecernos como una singular variación sobre la temática del deseo. No hay duda, en efecto, de que en la larga y compleja gestación de la obra, en el tránsito de las primeras églogas sueltas a la redacción provisional del Libro pastorale nominato Arcadio, hasta llegar a la configuración definitiva de la Arcadia en la edición

23. Todas las citas de la Arcadia están sacadas de la ed. cit. de Carlo Vecce. 
sulmontina, un dato parece imponerse con total evidencia ${ }^{24}$. Desde una fase a la otra de la realización de la obra, uno de los resultados que Sannazaro realizó progresivamente fue el de reducir la poesía bucólica a la esfera de la lírica, llevando a cabo, igualmente, un doble retorno, a Virgilio y a Petrarca. Se trata de una de las principales conclusiones del hermoso ensayo del añorado Edoardo Saccone, que -acerca de esto- afirmó: «Il genere pastorale [...] posto [...] da Sannazaro sotto il regno di Virgilio e Petrarca, si è andato in lui con chiarezza e coscienza via via crescenti, sempre più avvicinandosi, e a tratti risolvendosi nel genere lirico» ${ }^{25}$.

Recuperando el amor como tema predominante del género pastoril, con la Arcadia Sannazaro redujo la bucólica a la esfera de la lírica. En este sentido, el apego cada vez más convencido a la lección petrarquesca del Cancionero resultaba ineluctable, era un elemento -por así decirlo- preestablecido por el diseño que progresivamente se iba identificando y, al mismo tiempo, realizando, a medida que la obra procedía hacia la configuración definitiva, como atestigua la actividad correctora a la que Sannazaro, en los primeros años noventa, sometió a las églogas que, ampliadas a doce, sufrieron también -tal y como demostró Maria Corti- «un gioco sottile di rifacimenti e correzioni, maturati all'ombra pacificante del Petrarca» ${ }^{26}$.

La reducción de la bucólica al ámbito de la lírica constituye uno de los factores que más y mejor definen en general la renovación producida por la Arcadia, cuyas consecuencias fueron realmente múltiples, ya sea en el plano formal como en el temático. Por otra parte, uno de los efectos de mayor relevancia fue que la Arcadia se dejaba atrás, o, al menos, sometía a un redimensionamiento aquella "ridottissima diffrazione rispetto al reale» ${ }^{27}$, o sea, aquel "continuo ammiccare ${ }^{28}$ a los acontecimientos políticos y literarios de la vida ciudadana que -como sabemos- caracterizaba a la égloga del siglo XV. Se trata, en todo caso, de una reducción y no de una supresión o desaparición, puesto que, en la Arcadia, el elemento mencionado no solo está presente, sino que a veces es predominante, tal como sucede - por ejemplo- en las églogas sexta y décima, que con grandísima dificultad se dejarían atribuir al tema de amor, y donde, en cambio, emerge con fuerza la temática del "guasto del secolo» (egl. X, v. 193) en el mundo arcádico (la sexta), así como en el Reino de Nápoles (la décima).

Sobre esta lectura de la Arcadia, dirigida a privilegiar la dimensión éticopolítica de la obra y, por lo tanto, a identificar la denuncia del mal histórico presente y, en concreto, la de la dramática crisis del reino aragonés, han insistido

24. Como es sabido, la historia de la redacción de la Arcadia es muy compleja y sobre ella existen importantes estudios críticos. Aquí, es suficiente con remitir a la sintética exposición de Carlo Vecce, "Arcadia in movimento", ed. cit., pp. 43-47.

25. Edoardo Saccone, «L'Arcadia: storia e delineamento di una struttura», en $I l$ «soggetto» del Furioso e altri saggi tra Quattro e Cinquecento, Napoli, Liguori, 1974, p. 38.

26. Maria Corti, «Rivoluzione e reazione stilistica nel Sannazaro» (1968), en Metodi e fantasmi, op. cit., p. 311.

27. Giuseppe Velli, «Sannazaro e le "Partheniae Myrieae": forma e significato dell' Arcadia», en Tra lettura e creazione. Sannazaro - Alfieri - Foscolo, Padova, Antenore, 1983, p. 52, n. 36.

28. Corti, «Il codice bucolico», cit., p. 288. 
con un vigor especial los estudios de Santagata, Riccucci y Fenzi ${ }^{29}$. Este último, en uno de sus dos importantes trabajos dedicados a la cuestión, se ha expresado también en favor de una posición sobre la Arcadia en su conjunto que me atrevo a compartir, ya que el estudioso no duda en proponer la tesis, según la cual la Arcadia se va formando «stringendo in un sol nodo dimensione esistenziale e catastrofe storica», con una puntualización importante:

Credo si possa sostenere -escribe Fenzi- che la linea di sviluppo dell'Arcadia comporti due movimenti tendenzialmente contrari: il primo [...] colloca le punte recriminatorie e l'immediata vis polemica del travestimento bucolico in un contesto di forte liricizzazione; il secondo approfondisce e generalizza il senso ultimo di quelle accuse e mentre ne allontana il contenuto più episodico e personale le carica per contro di una assai più dolorosa valenza e insomma dell'esperienza ormai inevitabile a partire dalla metà degli anni '80 del secolo, della fragilità di un presente pronto ad essere inghiottito dall'abisso sul quale era affacciato. ${ }^{30}$

Mal de amor y mal histórico; proceso de liricización, por un lado, y tenaz, aunque no continuo, insinuarse a los asuntos políticos y literarios de la vida ciudadana, por otro: estos dos polos constituyen -para usar las palabras que acabo de citar de Fenzi- "due movimenti tendenzialmente contrari», como testimonio del hecho de que la Arcadia, lejos de ser concebida de manera unitaria, fue el resultado de un lento y difícil proceso de elaboración, que se

29. Por lo que se refiere a los dos primeros estudiosos, pueden verse Marco Santagata, "L'alternativa 'arcadica' del Sannazaro», en La lirica aragonese. Studi sulla poesia napoletana del secondo Quattrocento, Padova, Antenore, 1979, pp. 342-374. En la misma línea de una lectura "política» dell'Arcadia, Marina Riccucci, "Jacopo Sannazaro e la scelta del genere bucolico», en Guido D'Agostino y Giulia Buffardi (eds.), Atti del XVI Congresso Internazionale di Storia della Corona d'Aragona (Napoli 1977), Napoli, Paparo Edizioni, 2000, vol. II, pp. 1575-1602, y, con mayor extensión, el libro Il Neghitosso e il Fier Connubbio: Storia e filologia nell'Arcadia di Jacopo Sannazaro, Napoli, Liguori, 2001.

30. Enrico Fenzi, «Limpossibile Arcadia di Jacopo Sannazaro», en Pasquale Sabbatino (ed.), Jacopo Sannazaro. La cultura napoletana nell'Europa del Rinascimento, Firenze, Leo S. Olschki Editore, 2009, pp. 73 y 75. Pero, es igualmente importante el estudio complementario del mismo autor, «Arcadia X-XII», en Raffaele Girardi (ed.), Travestimenti: mondi immaginari e scrittura nella Europa delle corti, Bari, Edizioni di Pagina, 2009, pp. 35-70. En realidad, Giuseppe Velli ya había indicado una posible solución equilibrada en la interpretación de la obra maestra de Sannazaro, cuando, al denunciar «la sottovalutazione dello spessore letterario dell'opera» en la lectura "política» de Santagata, precisaba: «E nella Pastorale del De Jennaro, per la ridottissima diffrazione rispetto al reale, che si può leggere come in un palinsesto la minuta cronaca sociopolitica napoletana tra 1481 e 1486-87, non nell'Arcadia: se non con infinitamente più grande discrezione e con l'occhio in ogni caso alla funzione che alle egloghe impone la logica della struttura finale» (op. cit., p. 52, n. 36). Por mi parte, debo ahora hacer enmienda, confesando que también la lectura de la Arcadia propuesta por Edoardo Saccone, que privilegia casi exclusivamente el proceso de liricización con el que el literario napolitano renovaba la bucólica, en detrimento del elemento histórico y político, resulta bastante parcial, a pesar de que yo mismo me había adherido a ella, casi incondicionalmente, en un precedente trabajo, «La égloga en Nápoles entre Sannazaro y Garcilaso", en Con canto acordado, op. cit., pp. 216-239, que aquí retomo y corrijo, con significativas implicaciones para una diferente lectura también de la égloga de Garcilaso, que -como sugiero en las páginas siguientes- nace del intento de componer una obra en la cual confluyen el modelo bucólico sannazariano y el virgiliano. 
extendió a lo largo de quince años por lo menos, y que conoció tres diferentes fases redaccionales.

No hay duda de que este largo y muy complejo proceso de redacción es la causa del carácter compuesto, si no heterogéneo, de la obra, en la que también se deja asomar una cierta disparidad de concepción del género pastoril, oscilante entre la tendencia a adaptarse al modelo que se había afirmado en el siglo XV, y la mayor adhesión al carácter fuertemente innovador que la Arcadia confirió al género. A todo ello podemos añadir que, en la misma Arcadia, no faltan pasajes significativos, en los que emerge la relación entre la zampoña y la bocina o la trompa, o sea, entre el género pastoril y el épico (o heroico). En especial, en la décima prosa, el «savio sacerdote» Enareto traza a grandes rasgos una historia de la poesía pastoril, desde sus míticos orígenes por el «selvatico idio» Pan hasta el «mantuano Titiro»-Virgilio-, pasando por el «pastore siracusano», o sea, Teócrito. La mayor parte de dicha historia está dedicada, naturalmente, al poeta latino, del cual pasa revista -con la sola exclusión de la séptima y de la décima- a la mayor parte de las églogas, delimitando su temática; pues bien, -como advierte el mencionado Saccone- "l'amore sembra in effetti quasi l'unico tema, certo il predominante, che il Sannazaro intende sottolineare nelle bucoliche virgiliane ${ }^{31}$. Se trata, como es obvio, de una lectura tendenciosa de Virgilio, funcional a la propia definición de bucólica. Pero, dado que no todas las famosas composiciones del mantuano podían leerse en clave lírico-amorosa, Sannazaro se vio obligado a hacer decir a Enareto que el mantuano: "Non contentandosi di si umile suono, vi cangiò quella canna che voi ora vi vedette più grossa e piu che le altre nova, per poter meglio cantare le cose maggiori e fare le selve degne degli altissimi consuli di Roma» (p. 226). En otras palabras, no contento con el estilo humilde de la poesía pastoril, Virgilio sustituyó una de las siete cañas de las que ya estaba dotada la zampoña heredada de Pan y de Teócrito, con una caña "più grossa e più che le altre nova». Gracias a ella, el poeta latino pudo elevar el género pastoril a las "cose maggiori», es decir, a una poesía más noble y docta, que no es otra que el civile carmen ${ }^{32}$. Fue así como la humilde bucólica tuvo acceso a los nobles palacios, y las selvas fueron dignas de los grandes, con la cita literal del célebre verso de la cuarta bucólica virgiliana: «Si canimus silvas, silvae sint consule dignae».

Por este camino Sannazaro no podía seguir el modelo virgiliano, tal como declara de manera directa y explícita en el epílogo $A$ la sampogna, que compuso probablemente en Francia en 1503 y que mandó enseguida a sus amigos napolitanos ${ }^{33}$. En dicho epílogo, en efecto, el «peregrino d'amore», dando por terminada su experiencia arcádica, y con la mirada puesta en las «fatiche»

31. Saccone, op. cit., p. 15.

32. Para la expresión de civile carmen, véanse los versos de Giovanni del Virgilio: «... Si cantat oves et Tityrus hircos/aut armenta trahit, quianam civile canebas / urbe sedens carmen..." (Johannes de Virgilio Danti Alagherii Egloga responsiva, vv. 26-28, en Dante Alighieri, Opere minori, tomo II: De vulgari eloquentia, Monarchia, Epistole, Egloge, Questio de aqua et terre, ed. Pier Vincenzo Mengaldo et alii, Milano-Napoli, Riccardo Ricciardi Editore, 1979, pp. 674-676).

33. Retomo la hipótesis de Carlo Vecce, «Arcadia in movimento», en ed. cit., pp. 44-45. 
pasadas, se dirige a la «rustica e boscareccia sampogna» (p. 325), antes de alejarla para siempre de sus labios. Pues bien, aun reafirmando que "in altri tempi sono già stati pastori si audaci che insino a le orecchie dé romani consuli han sospinto il loro stile» (p. 329), recalcará que el destino que él reclama para su zampoña es distinto, exhortando al bajo instrumento a no seguir ese ejemplo, porque " $A$ te -dice- non ti appartiene andar cercando gli alti palagi de’ prencipi, né le superbe piazze de le populose cittadi» (p. 326). Por el contrario, su lugar será apartado, lejano de los aristocráticos palacios y de las atestadas ciudades: "Da boschi e da luoghi a te convenienti non ti diparta» (p. 328).

La razón de esta toma de posición está lo suficientemente clara, y el motivo se deja percibir de nuevo en el doble nivel sobre el que está construido todo el libro, es decir, a partir de los «dos movimientos tendencialmente contradictorios», de los que se ha hablado. Me explico. Si, en el plano de la dimensión existencial, o sea, del mal de amor y de la muerte de la joven amada, a la zampońa le corresponde la tarea de mostrar "le rispondenti selve di risonare il nome de la tua donna, e di piangere amaramente con teco il duro et inopinato caso de la sua immatura morte» (p. 326); es en el plano de la catástrofe histórica, o lo que es lo mismo, de la denuncia del mal histórico presente, donde la degradada realidad y la desastrosa situación partenopea, con el desplazamiento de la Arcadia a Nápoles, no le permiten a la zampońa de Sannazaro "cantare le cose maggiori», a diferencia de lo que le había sucedido a la zampoña heredada de Teócrito, que Virgilio había modificado con la sustitución de la caña "più grossa e più che le altre nuova». En efecto, ¿qué "alti palagi de prencipi» o qué «superbe piazze» habría podido, pues, buscar la zampoña de Sannazaro? O ¡a qué «orecchie de’ romani consuli» habrían podido ya espolear su estilo los audaces pastores de su Arcadia? En definitiva, ¿qué «cose maggiori» habría podido ya cantar el humilde sonido de la zampońa del poeta napolitano en un universo descrito en su ruina más absoluta, como de fin del mundo, y en el que -se lee en la despedida"ogni cosa si perde, ogni speranza è mancata, ogni consolazione è morta» (p. 328)?

En el nuevo contexto histórico de la Nápoles española de don Pedro de Toledo, las cosas, las esperanzas y las consolaciones que Sannazaro había dado por perdidas irremediablemente con el final del reino aragonés, vuelven a reanimarse y a prender nueva vida, permitiendo a un poeta como Garcilaso, ligado a la política imperial y al cargo asignado a su virrey, intentar, en su primer experimento del género eglógico, integrar en una única composición orgánica -en sus intenciones, al menos- la dolorosa materia amorosa, bajo cuyo signo Sannazaro realizó el proyecto de reducir la bucólica a la esfera de la lírica, y el canto de las "cose maggiori», al que había dado voz Virgilio en algunas de sus églogas. Lo confirma el exordio de la segunda parte de la égloga que, con la inicial invocación a las ninfas y a los faunos por parte de Nemoroso (vv. 1154-1160), marca una discontinuidad respecto al género bucólico, debido a la explícita referencia, si no a la grandeza del tema que se apresta a tratar, al menos a su carácter extraordinario: «Diré cosas estrańas y espantosas» -anuncia el pastor-, a las que no se adaptan ni los modos pastoriles, ni los instrumentos 
que los producen («que ni los [modos] pastoriles ni el avena / ni la zampońa suena como quiero", vv. 1158-1159) $)^{34}$. El lector de la égloga queda avisado, así, del tránsito al canto de las "cosas mayores», según la lección virgiliana ("paulo maiora canamus», Buc., IV, 1), para las que es necesario un estilo más alto, que sea dictado directamente por las semi-divinidades de los bosques invocadas por Nemoroso. De hecho, en la segunda mitad de este proemio, el panegírico se introduce como la representación de la vida y de las hazañas del joven Fernando, esculpidas en la «labrada y cristallina urna» por el viejo Tormes, presentado como una divinidad fluvial con figuración antropomórfica (vv. 1161-1180).

Pues bien, aunque cada uno de los tres motivos que componen el artificio (profecía, écfrasis, figuración antropomórfica de una divinidad fluvial) tiene una larga tradición a sus espaldas, hasta llegar al pabellón profético del último canto del Orlando furioso (para los dos primeros motivos, al menos) ${ }^{35}$, es probable que Garcilaso tomase el expediente narrativo de una breve escena del De partu Virginis (1526) del mismo Sannazaro, donde el río Jordán es presentado reclinado sobre una urna ("pronaque acclinis in urna») ${ }^{36}$, en la que se encuentra la representación esculpida de carácter profético del episodio evangélico que relata cómo Juan el Bautista bautiza a Jesús en las aguas del río Jordán ${ }^{37}$. Pero, con una operación de concatenación de textos clásicos y contemporáneos, que es típica del arte poético garcilasiano, el toledano adapta el artificio obtenido, en primera instancia, de la obra de épica cristiana del admirado poeta napolitano a un contexto de épica laica, por lo que la referencia es ahora al doble episodio del libro VIII de la Eneida virgiliana: el relativo al río Tíber que profetiza a Eneas, en sueños, la victoria sobre los latinos (vv. 36-65) y el de la descripción del escudo fabricado por Vulcano y regalado a Eneas por su madre Venus, en el que el dios del fuego había grabado «res Italas Romanorumque triumphos [...] genus omnes futurae / stirpis ab Ascanio pugnataque in ordine bella» (vv. 626-629, «Hechos de Italia y triunfos Romanos [...]. La descendencia toda / estaba allí de Ascanio, con las guerras en las que

34. Todas las citas de la égloga II están sacadas de la ed. cit. de Bienvenido Morros.

35. Se trata, como se sabe, del pabellón profético (el «ricco padiglion trapunto») con el elogio de Ippolito d'Este (XLVI, 85-97), que había sido bordado por la troyana Casandra y que Melissa maga había recuperado y aparejado para las bodas de Ruggiero y Bradamante. El Brocense fue el primero en señalar el último canto del Orlando furioso con relación a los versos de los genetlíacos de Ippolito y de Fernando (ed. cit. de Gallego Morell, p. 295, B-193-195 y B-197).

36. Sannazaro, De partu Virginis, eds. Charles Fantazzi y Alessandro Perosa, Firenze, Leo Olschki Editore, 1988, 1. III, v. 298, p. 73. Véase también del mismo Sannazaro, Arcadia: "Trovai in terra sedere il venerando idio [el río Sebeto], col sinestro fianco appoggiato sovra un vaso di pietra» (prosa XII, 37, p. 243). Para las fuentes clásicas de Sannazaro, que Garcilaso también conocía, véanse Estacio, Thebaida, II, 217-218, y Claudiano, De raptu Proserpinae, II, 69-70. La señalización del texto latino de Sannazaro como fuente de Garcilaso se debe a Eugenio Mele, «In margine alle poesie di Garcilaso", Bulletin Hispanique, vol. 32, 1930, p. 225.

37. El episodio completo en Sannazaro, De partu Verginis, ed. cit., 1. III, vv. 298-317. 
había de luchar») ${ }^{38}$. No es casual que, en el comentario de Donato, los versos sobre el escudo de Eneas sean interpretados en clave epidíctica, ya que

\begin{abstract}
quae futurorum praescius Vulcanus in clipeo expresserat, poeta vero de rebus iam gestis et ipsis triumphis Caesaris doctus praecipua inventione textum ipsum descriptionemque complexus est, ut Caesaris praesentis gesta laudaret. [Las cosas futuras que el présago Vulcano había representado en el escudo, el docto poeta en realidad reunió en una singular invención la misma narración y descripción de cosas ya acaecidas con los mismos triunfos de César, con el fin de alabar las hazañas del actual César]. ${ }^{39}$
\end{abstract}

Pero es útil recordar que la posibilidad de una elevación de estilo y de un canto de "cose maggiori» había aflorado concretamente también en la Arcadia, cuando, justo al final de la prosa VII, después de haber escuchado el relato de Sincero, Carino le había deseado al desgraciado pastor napolitano que «gli dii ne le braccia ti rechino de la desiata donna» (p. 165) y, además, al prometerle como don su zampońa de saúco, le había anunciado que con esta flauta o siringa de calidad superior

(se da li fati non ti è tolto), con più alto stile canterai gli amori di fauni e di ninfe nel futuro. E si come insino qui i principii de la tua adolescenzia hai tra semplici e boscarecci canti di pastori infruttuosamente dispesi, cosi per lo inanzi la felice giovenezza tra sonore trombe di poeti chiarissimi del tuo secolo, non senza speranza di eterna fama trapasserai (p. 166).

Un doble auspicio, pues, en el que a la superación de la melancolía amorosa, gracias a la satisfacción de su deseo con la "picciola fanciulla» se juntaba el pronóstico con el que Carino predecía que Sincero, con su nueva flauta o siringa, se dedicaría, por un lado, a una poesía más alta, siempre de inspiración bucólica y mitológica, y, por otro lado, emplearía su feliz juventud -tal como parece indicar el cambio de instrumento (las «sonore trombe») - en una elevación de estilo y de género: la épica, con la celebración de los príncipes aragoneses, según el modelo bucólico que se había impuesto en las églogas virgilianas.

Un augurio que-como saben muy bien los lectores de la Arcadia- al final del viaje de Sincero, con su regreso a Nápoles, resultará doblemente incumplido, puesto que el pastor no será acogido por la «desiata donna» entre sus brazos, sino por la trágica noticia de su muerte; y, sobre todo, porque la dramática situación en la que ha precipitado el reino aragonés y la ciudad de Nápoles impide cualquier manifestación de las «sonore trombe» anunciadas por Carino: en lugar del canto de alabanza al actual «nobile secolo» solicitado a Selvaggio, un «doble» de Sincero, el Libro pastorale nominato Arcadio se concluía con la égloga décima, o sea, con el fúnebre lamento, en el que Caracciolo reprobaba con rabia el "guasto secolo» (egl. X, v. 193), la realidad del mal presente; así como en la redacción definitiva de la Arcadia, "en el lenguaje alusivo y profético» que

38. El episodio virgiliano del escudo de Eneas fue indicado por Georges Cirot, «Ronsard et les Espagnols», Bulletin Hispanique, vol. 44, 1942, p. 169.

39. Ad Aen. VIII, 731. Cito de Tiberio Claudio Donato, Interpretationes Virgilianae, ed. Heinricus Georgius, Leipzig, Teubner, 1905-1906, II, p. 182. 
Sannazaro adopta en los últimos capítulos y en el epílogo ${ }^{40}$, tampoco hay la más mínima evocación de aquellas «sonore trombe», que deberían conquistar los «sonanti plausi» en los «alti palagi de' prencipi» o en las «superbe piazze delle populose cittadi». Al contrario, la obra termina con el «umile suono» y el llanto de la zampońa, a la que el autor dirige la extrema súplica: «Che de la tua selvatichezza contentandoti tra queste solitudini ti rimanghi» (p. 325).

Para retomar la expresión de la que hemos partido, a propósito de la obsesión amorosa de Clonico, resulta evidente que en la Arcadia de Sannazaro no existe ningún «rimedio al male», y ello se verifica en el doble plano sobre el que está construida la obra: no lo hay ni por lo que atañe a la "dimensión existencial»

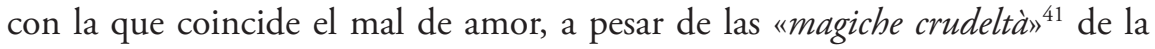
bruja-hechicera de la prosa IX, o del mismo Enareto en la prosa X; ni por lo que concierne a la "catástrofe histórica», respecto a la cual la obra traza «un percorso di crescente rovina che non lascia spazio che allimpotenza e alla disperazione» ${ }^{42}$.

Volviendo a la égloga de Garcilaso, el cambio sufrido por el contexto histórico y literario -como ya he dicho- permitía al poeta toledano completar aquella operación que, en la ficción de la Arcadia, «una delle opere più nere della nostra letteratura» ${ }^{43}$, según Fenzi, a Sincero-Sannazaro le había sido pronosticada por Carino, pero que luego le había sido impedida en el momento del regreso a la patria chica, tanto en el plano personal, a causa de la muerte de la amada, como en el de la realidad histórica, con la desastrosa situación del Reino y de la ciudad de Nápoles. De este modo, mientras en el citado epílogo $A$ la sampogna, Sannazaro había ratificado perentoriamente la incompatibilidad de género pastoril y género épico: "Il tuo umile suono -había escrito- mal si sentirebbe tra quello de le spaventevoli buccine e de le reali trombes (p. 326), en la égloga segunda, a Garcilaso lo animaba el propósito de fundir el sonido de la bucólica zampońa con el de la trompa militar. En otras palabras, un contexto histórico-literario completamente transformado permitía a Garcilaso integrar en una única composición la bucólica vulgar del admirado poeta napolitano y la clásica del no menos amado poeta latino. De la revolucionaria obra del primero obtenía el relato de la infeliz historia de amor del pastor Albanio, transcrita del arcádico Carino; de la renovadora égloga cuarta del segundo y de su famosísimo incipit conseguía la licencia de cantar «cose maggiori», con la profecía de una «nova progenies» (v. 7) y el nacimiento de un «puer», «quo ferrea primum / desinet ac toto surget gens aurea / mundo» (vv. 8-9, "por quien [el niño] por primera vez se extinguirá la raza de hierro y en el mundo entero surgirá la raza de oro»). Así como los versos inmediatamente posteriores de la égloga virgiliana, con las benignas repercusiones en el mundo del nacimiento del puer y de su acción, debieron de ejercer una influencia semejante en la ideación de la égloga garcilasiana, porque con él, o gracias a él, «decus hoc aevi [...] inibit»

40. Fenzi, «Limpossibile Arcadia», cit., p. 70.

41. Ibid., p. 90.

42. Ibid., p. 90.

43. Ibid., p. 90. 
(v. 11, «dará principio esta edad gloriosa»), e ille -el niño mismo- "pacatumque reget patriis virtutibus orbem» (vv. 13-14, «regirá el mundo apaciguado con las virtudes de su padre»), ya que «si qua manent sceleris vestigia nostri, I inrita perpetua solvent formidine terras» («si algunas huellas perduran de nuestro crimen, su ineficacia librará a la tierra de una perpetua zozobra») ${ }^{44}$.

El sentido de la pieza de Virgilio, a la que hace eco la de Garcilaso, está todo aquí: en el tránsito del scelus, o sea, de la decadencia moral y de la maldad de los mortales, al decus, el esplendor de la nueva edad de oro, con el canto profético y celebrativo del puer, cuyo nacimiento garantiza la llegada de una nueva época. En la égloga de Garcilaso, asistimos a un tránsito análogo del mal de amor que corrompe el alma humana arrebatándola de su naturaleza: «Fuera de libertad y de reposo" (v. 1109), el mal como depravación moral encarnada por Albanio y su historia, a la «virtud sublimada» (v. 1786) de Fernando, cuyo esplendor -con simbología solar- es tal que ciega la vista humana, como el deslumbramiento que sufre quien de repente ve el sol tras una larga estancia en lugar oscuro. Como Virgilio, pues, y a diferencia de Sannazaro, Garcilaso se reviste la túnica del vates, del profeta cantor de algo nuevo, y la égloga se convierte en canto profético y celebrativo; en especial, con la segunda mitad de la égloga, Garcilaso inaugura -tal y como he intentado demostrar en un trabajo dedicado a dicho asunto-, en la literatura española -y, quizás, en la moderna literatura en vulgar- el panegírico en versos, construido respetando rigurosamente los esquemas retóricos clásicos del basilikòs lógos, según el modelo ofrecido por el doble canal: el de la preceptiva que regulaba la oratoria epidíctica, en el plano teórico, y, en el de la práctica, el canal de la imitación de los más consagrados ejemplos ${ }^{45}$.

En un estudio de hace unos pocos años, Bienvenido Morros ha reconstruido con mucha perspicacia y variedad de argumentos la unidad y la coherencia de la égloga segunda. Sin embargo, no creo que sea estrictamente necesario identificar al pastor Albanio con Don Fernando, tercer duque de Alba, aunque, en verdad, no le han faltado buenas y diferentes razones a Bienvenido para sostenerlo. Claro que, si no se quiere renunciar a dicha identificación, la respuesta que el autor del estudio da a la justa pregunta que él se pone: «¿Qué pretendió [Garcilaso] al componer una obra tan heterogénea y dispar?», es ciertamente la que él mismo sugiere: «Rendir homenaje a quien más le había ayudado en los momentos difíciles», o sea, el gran duque, don Fernando ${ }^{46}$. Pero se trata de una respuesta que, aun siendo lógica y conveniente, no es del todo suficiente. Como no lo sería, por otra parte, si, a propósito de su cuarta bucólica, y del esfuerzo realizado con ella por distinguirse de la tradición teocritea (le «Sicelides Musae» de la innovación inicial), nos limitáramos a

44. Las traducciones de Virgilio están tomadas de Virgilio, Obras completas, ed. Marcial Olivar, Barcelona, Montaner y Simón S. A., 1976.

45. Cf. Antonio Gargano, "Las estrañas virtudes y hazañas de los hombres”. Épica y panegírico en la Égloga Segunda de Garcilaso de la Vega», Criticón, no 115, 2012, pp. 11-43.

46. Bienvenido Morros, «Vida y poesía de Boscán y Garcilaso. A propósito del Gran Duque de Alba», Boletín de la Biblioteca de Menéndez Pelayo, LXXXIV, 2008, pp. 13-58. 
afirmar que Virgilio quiso exclusivamente homenajear a su amigo y protector, el cónsul Asinio Polión, y no, en cambio, y junto con ello, trazar el diseño político, frente al temor de un derrumbe general del imperio, con el anuncio de una nueva era, de un nuevo saeculorum ordo, con el retorno a la edad feliz de Saturno, después de los desastres de la guerra civil y la crisis del mundo antiguo.

La égloga segunda de Garcilaso no se queda atrás. En este sentido, me limitaré, para concluir, a esbozar velozmente el amplio trazado de civilización humana que la obra parece querer explorar, a través de la escansión del tiempo de la historia de la humanidad, entre mito y profecía.

En efecto, detrás de la aparente falta de "cohesión estética» o detrás del defecto exterior de "unidad intrínseca», se deja entrever un coherente diseño unitario que está basado en la construcción de una triple dimensión temporal: la de un tiempo mítico, histórico y profético en los que la égloga articula la narración del desarrollo de las vicisitudes humanas. Como mera hipótesis destinada a ser rigurosa y puntualmente formulada y verificada, podemos conjeturar en extrema síntesis que la égloga segunda de Garcilaso es, entre otras muchas cosas, una obra en la que se articulan, alternándose, tres tiempos de la evolución humana, individual y colectivamente considerada, ya que a la edad mítica representada por los "puerili anni»" ${ }^{47}$, durante los cuales Albanio y Camila pueden sentir el uno por la otra un sentimiento de puro afecto, sigue el tiempo de la historia y de la edad adulta que, marcado por la insatisfacción del deseo y su consiguiente sufrimiento, será superado solo por un tiempo profético, en el que la promesa de que el mal será curado y de que el alma enferma será devuelta a su naturaleza (vv. 1125-1127) se acompaña a la écfrasis representada en la urna de cristal del viejo Tormes, donde con el anuncio de una noble estirpe se pronostica también el triunfo de las virtudes febeas y del amor conyugal frente al desorden de la pasión ${ }^{48}$.

47. La expresión se lee en Sannazaro, Arcadia, ed. cit., pr. VII, p. 159.

48. He propuesto dicha hipotesis de lectura de la égloga, según un coherente diseño unitario, en un breve trabajo, sobre el episodio de la caza en la prosa VII de la Arcadia y en la égloga segunda de Garcilaso, para ello cf. Antonio Gargano, «En los orígenes del moderno género bucólico: La Égloga segunda de Garcilaso», en Teresa Rodríguez y Florence Raynié (eds.), Dire, taire, masquer les origines dans la péninsule Ibérique du Moyen Âge au Siècle d'Or, Toulouse, CNRS - Université de Toulouse-Le Mirail, 2013, pp. 163-170. 
